\title{
Contaminated Land, Ecological Assessment, and Remediation Conference Series (CLEAR 2014): environmental remediation with advanced materials
}

\author{
Hailong Wang ${ }^{1}$ Yong Sik $\mathrm{Ok}^{2}$
}

Received: 23 November 2015 / Accepted: 27 November 2015 /Published online: 15 December 2015

(C) Springer-Verlag Berlin Heidelberg 2015

The Contaminated Land, Ecological Assessment and Remediation Conference Series (CLEAR) provides an international platform for scientists, consultants, and policy makers to interact. The target audience is those who are responsible for improving and protecting our environment in order to cope with rapid industrial development. The first CLEAR conference (CLEAR 2012) was held in Hangzhou, China in November 2012 and the second (CLEAR 2014) in Chuncheon, Korea in October, 2014.

The CLEAR 2014 conference focused on the issues of environmental pollution, remediation, and risk assessment. A number of special symposiums were held during the conference including Biochar for Environmental Management (joint with 2nd KBRC International Biochar Symposium), Novel Adsorbents and Nanomaterials for Contaminant Removal from Water and Wastewater, Pharmaceuticals in the Soil Environment: Fate and Effects in Soil and Transfer to the Food Chain, Heavy

Responsible editor: Philippe Garrigues

Hailong Wang

nzhailongwang@gmail.com; hailong@zafu.edu.cn

Yong Sik Ok

soilok@kangwon.ac.kr

1 Key Laboratory of Soil Contamination Bioremediation of Zhejiang Province, Zhejiang A \& F University, Lin'an, Hangzhou, Zhejiang 311300, China

2 Korea Biochar Research Center, School of Natural Resources and Environmental Science, Kangwon National University, Chuncheon 200-701, South Korea
Metal Remediation in Agricultural Ecosystems, and Rapid Pollutant Transport from Farmland to Water Bodies: Mechanisms and Mitigation. The CLEAR 2014 conference attracted more than 350 participants from over 30 countries and facilitated considerable information exchange regarding land contamination, risk assessment, and remediation. This special issue of ESPR is a collection of selected contributions from the CLEAR 2014 conference participants and is published after a stringent peer-review process. The special issue mainly covers topics related to the environmental functions of advanced materials (such as carbon nanotubes, biochar, etc.).

As Guest Editors, we would like to thank the authors, reviewers, and fellow ESPR editors for their hard work and contribution towards this special issue. We would also like to thank Prof. Philippe Garrigues, the Editorin-Chief of ESPR, for his kind invitation to publish this special issue. 


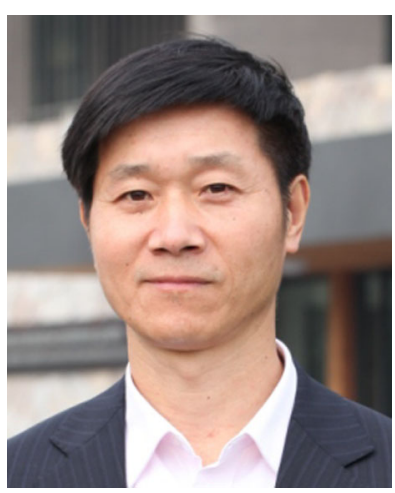

Dr. Hailong Wang is a distinguished professor at the School of Environmental and Resource Sciences, Zhejiang A \& F University. He is the director of the Key Laboratory of Soil Contamination Bioremediation of Zhejiang Province, China. As an environmental soil scientist, his research focuses on biochar and its effect on ecosystems, remediation of contaminated soils, nutrient management in relation to surface water eutrophication, and soil carbon sequestration related to land use. In addition, he applies stable isotope techniques to trace the fate and movement of important elements (e.g., nitrogen and carbon) in ecosystems. Prof. Wang currently serves as a member of the International Biochar Initiative (IBI) Advisory Committee and Industry Committee and a deputy coordinator of the Forest Soils and Nutrient Cycles Unit in the International Union of Forest Research Organizations (IUFRO). He is an expert of international standing that assesses funding applications for the Australian Research Council, an editor of Environmental Science and Pollution Research and Journal of Soils and Sediments, and a member of the editorial board of Waste and Biomass Valorization.

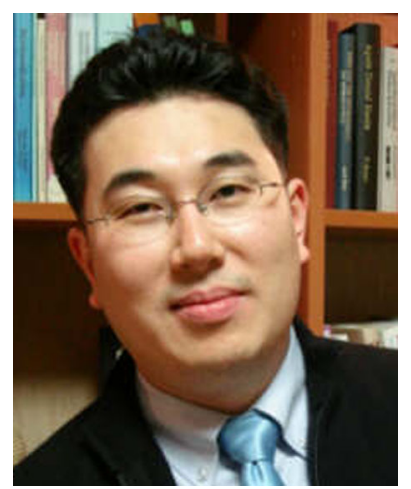

Dr. Yong Sik Ok is a Full Professor at the School of Natural Resources and Environmental Science, Kangwon National University (KNU) and is currently serving as the Director of the Korea Biochar Research Center (KBRC) in Korea. Prof. Ok is currently the Coordinating Editor for Environmental Geochemistry and Health, a Subject Editor for Journal of Soils and Sediment, an Associate Editor for Canadian Journal of Soil Science, and an Editorial Board Member for Chemical Speciation and Bioavailability. Additionally, he has served as a Guest Editor for the leading journals including Bioresource Technology, Journal of Hazardous Materials, Chemosphere, Plant and Soil, Journal of Environmental Management, Environmental Science and Pollution Research, Environmental Geochemistry, and Health, Geoderma, Journal of Soils and Sediments among others. As a Visiting Professor, Prof. Ok contributes to the Department of Renewable Resources, University of Alberta (Canada), the Faculty of Bioscience Engineering, Ghent University (Belgium), and the Department of Civil and Environmental Engineering, Hong Kong Polytechnic University (Hong Kong). Prof. Ok has organized many international conferences including, most recently, CLEAR 2014 (Korea) and Biological Waste 2014 (Hong Kong). 